\title{
Article \\ The Effect of Salinity on Fruit Quality and Yield of Cherry Tomatoes
}

\author{
Carlos Agius ${ }^{1, * \mathbb{C}}$, Sabine von Tucher ${ }^{1}$ and Wilfried Rozhon ${ }^{1,2, *(1)}$ \\ 1 TUM School of Life Sciences Weihenstephan, Technical University of Munich, 85354 Freising, Germany; \\ tucher@wzw.tum.de \\ 2 Department of Agriculture, Ecotrophology, and Landscape Development, \\ Anhalt University of Applied Sciences, 06406 Bernburg, Germany \\ * Correspondence: carlos.agius@tum.de (C.A.); wilfried.rozhon@hs-anhalt.de (W.R.); \\ Tel.: +49-8161-71-2879 (C.A.); +49-8161-71-2023 (W.R.)
}

Citation: Agius, C.; von Tucher, S.; Rozhon, W. The Effect of Salinity on Fruit Quality and Yield of Cherry

Tomatoes. Horticulturae 2022, 8, 59. https://doi.org/10.3390/

horticulturae 8010059

Academic Editor: Luigi De Bellis

Received: 18 December 2021

Accepted: 5 January 2022

Published: 8 January 2022

Publisher's Note: MDPI stays neutral with regard to jurisdictional claims in published maps and institutional affiliations.

Copyright: (c) 2022 by the authors. Licensee MDPI, Basel, Switzerland. This article is an open access article distributed under the terms and conditions of the Creative Commons Attribution (CC BY) license (https:// creativecommons.org/licenses/by/ $4.0 /)$.

\begin{abstract}
Hydroponic cultivation of vegetables avoids problems with soil-borne plant pathogens and may allow higher yield. In arid climates and particularly on islands, high concentrations of sodium chloride can be present in the groundwater. For instance, in many sites of Malta, the groundwater contains more than $10 \mathrm{mM}$ sodium chloride. Here we investigated the effects of sodium chloride at levels typically found in Malta on yield, physiology and fruit quality of tomato, the economically most important vegetable. We selected cherry tomatoes since their production is attractive due to their high marketing value. While the yield declined at higher salinity levels tested (17 and $34 \mathrm{mM}$ ), the quality increased significantly as indicated by higher total soluble solids and fructose and glucose levels. The type of substrate-coco peat, perlite or Rockwool-had only minor effects. Although the concentration of citric acid and malic acid remained unaffected, the $\mathrm{pH}$ dropped by approximately 0.1 unit and the titratable acidity increased slightly. This might be explained by a high uptake of chloride but a lower increase of the sodium content and a reduced potassium level in the fruits, shifting the equilibrium of the organic acids more to their protonated forms. Proline increased significantly, while the level of glutamic acid, which is crucial for the taste, remained unchanged. Our results show that cherry tomatoes can be cultivated in nutrient solutions prepared with salt-containing groundwater, as found in Malta. The yield declined to some extent but the quality of the produced fruits was higher compared to cultivation in salt-free media.
\end{abstract}

Keywords: amino acids; nutrients; salinity; sugars; titratable acidity; tomato; yield

\section{Introduction}

Tomato (Solanum lycopersicum) is one of the economically most important horticultural crops with 181 million tons having been produced worldwide in 2019 [1]. Originating from the Andes region in South America, tomato is now grown all over the world. Determinate varieties, which stay short and form multiple flower clusters, are commonly grown in the field and machine harvested. They are used to produce tinned tomatoes, tomato sauce, ketchup and other processed products. In contrast, tomatoes grown for fresh consumption are nowadays cultivated mainly in protected culture. For this purpose, indeterminate varieties are preferred, which can reach a final length of more than $6 \mathrm{~m}$ during the production period of typically 6 to 9 months [2,3]. Traditionally, tomatoes were soil-grown in greenhouses. This practice caused severe problems including rapid soil erosion, difficulties in appropriate plant nutrition and particularly an increase in soil-borne pests and diseases. These drawbacks were overcome by soilless cultures, where the plants are grown in inert substrates continuously supplied with nutrient solutions, which allows optimal control of mineral nutrition of the plant [4]. Because of its high pore volume, consistent quality, simple control of the cultivation system and increased yield compared to soil culture, Rockwool was the first widely used substrate [5]. Perlite is another popular 
choice of substrate for growing tomatoes. It is commonly filled into plastic bags or Bato buckets [2]. However, as mineral-based materials, used Rockwool and perlite create a waste problem. An alternative with increasing popularity is coco peat, which is extracted from the outer hull of coconut and used in growth bags similar to perlite or Rockwool. After use coco peat can be composted. The yield of tomato grown in either coco peat, perlite and Rockwool was reported to be almost identical [6,7]. In contrast to Rockwool and perlite, which have no significant cation exchange capacity, coco peat has a cation exchange capacity of 320 to $950 \mathrm{mmol}_{\mathrm{C}} \cdot \mathrm{kg}^{-1}$ [8] and has therefore some cation buffering capacity.

However, for crucial anions including nitrate, sulphate and phosphate none of the substrates has significant buffering capacity. Due to the restricted root volume and low ion buffering capacity, the amount of irrigation water and its content of nutrients must be carefully controlled [5]. Depending on the growth stage, tomato plants have different nutrient requirements. For instance, in periods of leaf growth elevated amounts of calcium are required while at full fruit load the uptake of potassium increases strongly. A high supply of potassium during fruit ripening enhances yield, shelf life, and taste of tomatoes but also increases the risk of blossom end rot [5]. In addition, the tomato also has a high demand for nitrogen during fruit ripening since tomato fruits contain high levels of free amino acids, particularly glutamate $[9,10]$, which is also believed to be an important factor for its taste $[11,12]$.

The total concentration of nutrients is usually kept in the range of 1.5 to $3.5 \mathrm{mS} \cdot \mathrm{cm}^{-1}$ since optimal yield is obtained in this range [5]. This requires the use of high-quality water with low concentrations of sodium chloride for preparing growth media, particularly for closed growing system. However, in arid and semi-arid climates, for instance, the Mediterranean region, water with low contents of minerals is hardy available. On islands, the situation is even worse because precipitation is often low, and groundwater may contain significant amounts of minerals. On islands, groundwater is present as a so-called Ghyben-Herzberg lens, where freshwater water originating from precipitation is present in the central zone. Closer to the shore, the aquifers come in contact with seawater and the groundwater gets brackish. In Malta, the chloride and sodium concentrations of groundwater can, depending on the site of the pumping station, vary significantly from 106 to $2431 \mathrm{mg} \cdot \mathrm{L}^{-1}$ and 63 to $1517 \mathrm{mg} \cdot \mathrm{L}^{-1}$, respectively (Figure 1) [13]. Consequently, nutrient solutions prepared from such resources contain considerable concentrations of sodium chloride.

A

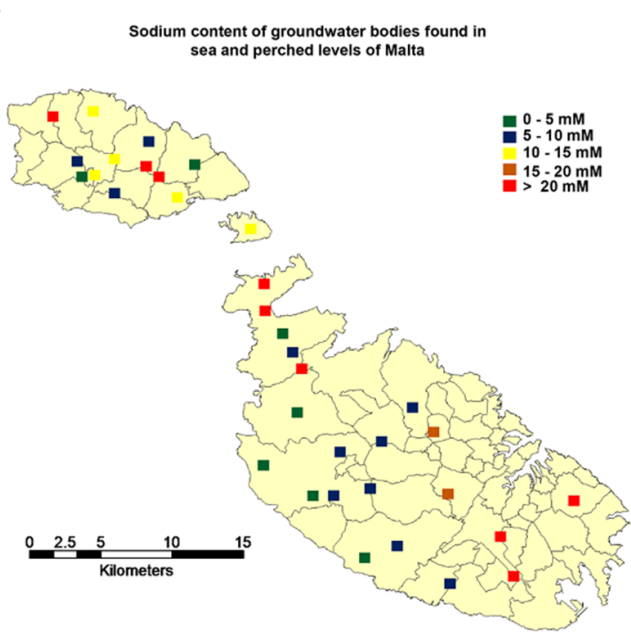

B

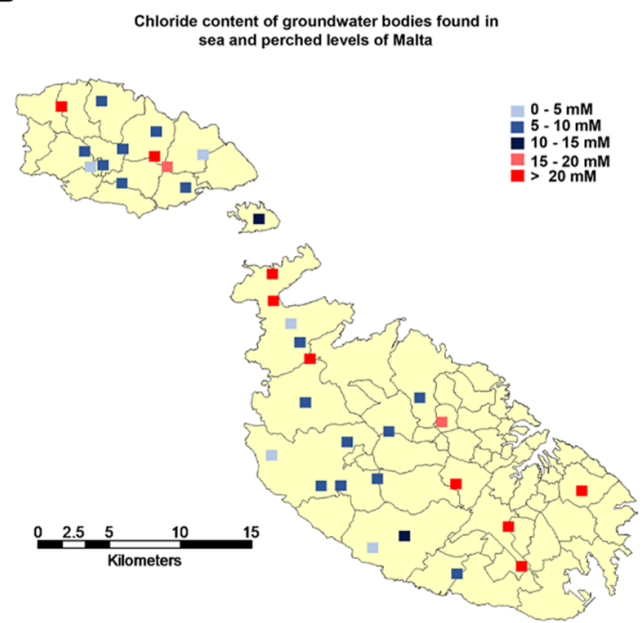

Figure 1. Concentration of sodium (A) and chloride ions (B) in groundwater in Malta. Data were taken from [13].

Sometimes increased salinity of up to $5 \mathrm{mS} \cdot \mathrm{cm}^{-1}$ in nutrient solutions for tomato cultivation is desired since this leads to a higher fruit quality [14]. The increased concentration 
can be achieved by either increasing the concentrations of the nutrients or by presence of salts like sodium chloride. Tomatoes grown in nutrient solutions with increased salt content show increased fruit firmness and cuticle thickness [15-17]. In contrast, the salinity of irrigation water was reported to have no significant impact on fruit firmness in soil grown tomatoes [18]. However, that might be attributed to the cation buffering capacity of soil. Moreover, tomatoes grown in nutrient solutions have been reported to show increased salt sensitivity [5]. Besides physical parameters also the chemical composition of tomato fruits is significantly affected by high salinity. Particularly the total soluble solids, titratable acidity, organic acids and free amino acids including $\gamma$-aminobutyric acid were reported to be increased, which enhances fruit quality [16,19-22]. However, sodium chloride also causes nutritional imbalance by decreasing potassium and phosphate uptake [23] and lowering, in addition, the levels of calcium, magnesium, and iron in the shoots [24,25]. Furthermore, it negatively impacts photosynthesis and stressed leaves display lower stomatal pore area and stomatal index [26].

While effects of sodium chloride on physiology, development and yield are well studied in round tomato, its effects on cherry tomatoes are less well-researched [27-29]. In cherry tomatoes, total soluble solids, which are mainly constituted by soluble sugars, and the titratable acidity are higher than in round tomatoes even when grown in the absence of salt stress [30,31]. Previously, it has been reported that salt stress reduces stomatal conductance, leaf area, and plant biomass while it increases the percentage of dry weight in leaves and fruits [28]. In another study, it was shown that titratable acid and proline, an important osmolyte, increased under salt stress conditions in tomato leaves while their content of soluble sugars decreased [29]. Higher titratable acidity was also found in cherry tomato fruits under salt stress [27]. While sugars were reported to decrease in tomato leaves under salt stress, in tomato fruits, higher sugar concentrations were also found. In addition, the levels of antioxidants were increased in cherry tomato fruits under salt stress [27].

Here we wanted to investigate the impact on sodium chloride levels typically found in Malta on the yield, growth performance and physiology of cherry tomatoes. With respect to the chemical composition of fruits, particularly the impact on the sugars, glucose and fructose, as well as the organic acids, citric acid, and malic acid, were of interest, since they are important factors for taste. In addition, we investigated the levels of ions and free amino acids since alterations of these compounds in cherry tomato fruits under salt stress remained so far elusive.

\section{Materials and Methods}

\subsection{Seeding of Tomato}

Seeds of Solanum lycopersicum cv. Gustafano (Enza Zaden Germany, Dannstadt-Schauernheim, Germany) were germinated in $3.6 \times 3.6 \mathrm{~cm}$ Rockwool plugs (Grodan Rockwool Transplanting/Propagation Mat, Grodan, Roermond, The Netherlands). Tomato seedlings intended to be transplanted into Rockwool and perlite were transferred into wetted $7.5 \times 7.5 \times 6.5 \mathrm{~cm}$ Rockwool blocks (GrodanDelta Gro-Block, Grodan, Roermond, The Netherlands) whilst those planned to be grown in coco peat were transferred in wetted $8 \times 8 \times 6.5 \mathrm{~cm}$ coco peat blocks (Jiffy Coco Block, Jiffy Products International BV, Zwijndrecht, The Netherlands). Two weeks after germination, a nutrient solution containing $5.7 \mathrm{mM}$ nitrate, $1.3 \mathrm{mM}$ phosphate, $3.8 \mathrm{mM}$ potassium, $2.0 \mathrm{mM}$ calcium, $0.82 \mathrm{mM}$ magnesium, $0.62 \mathrm{mM}$ sulphate, $27 \mu \mathrm{M}$ boric acid, $0.3 \mu \mathrm{M}$ molybdate and EDTA-complexes of $20 \mu \mathrm{M}$ iron(III), $15 \mu \mathrm{M}$ manganese, $2 \mu \mathrm{M}$ zinc and $1 \mu \mathrm{M}$ copper was fed. The $\mathrm{pH}$ of the nutrient solution was maintained in the range of 5.4 to 6.5 with $43 \%$ phosphoric acid.

\subsection{Growth Conditions}

Tomato plants were grown in a single-span climate-controlled greenhouse located in Dürnast, Freising, Germany ( $\left.48^{\circ} 24^{\prime} 18.2^{\prime \prime} \mathrm{N} 11^{\circ} 41^{\prime} 20.9^{\prime \prime} \mathrm{E}\right)$. The mean air temperature inside the greenhouse for the growing period from May until October was of $22.0 \pm 5.2^{\circ} \mathrm{C}$, with maximum and minimum temperatures of $42.9{ }^{\circ} \mathrm{C}$ and $15.8{ }^{\circ} \mathrm{C}$, respectively. The 
relative humidity $(\mathrm{RH})$ in the greenhouse from May until October was $58.3 \pm 16.2 \%$, with a maximum and minimum of $92.4 \%$ and $13.29 \%$, respectively. The air temperature and humidity of each month in the greenhouse are specified in Supplementary Table S1.

Tomato seedlings were transplanted on Rockwool, perlite, and coco peat grow bags. The Rockwool bags used had a size of $1.0 \mathrm{~m} \times 0.15 \mathrm{~m} \times 0.075 \mathrm{~m}$ and a volume of $11.3 \mathrm{~L}$ (Grodan Grotop Master, Grodan, Roermond, The Netherlands). Perlite grow bags were prepared by filling 2-6 mm perlite (PERLIGRAN ${ }^{\circledR}$ Extra, Knauf Performance Materials $\mathrm{GmbH}$, Dortmund, Germany) in transparent plastic bags, which were heat-sealed and wrapped with white on black plastic foil. The dimensions of the perlite grow bags were $1.0 \mathrm{~m} \times 0.15 \mathrm{~m} \times 0.11 \mathrm{~m}$ with a volume of $16.5 \mathrm{~L}$. The dimensions of the coco peat bags were $1.0 \mathrm{~m} \times 0.15 \mathrm{~m} \times 0.10 \mathrm{~m}$ and had a volume of $15 \mathrm{~L}$ (UGro Slab Mix3, Simply Organic S.L., El Masnou, Barcelona, Spain). The coco peat had the following specification: bulk density of $0.52 \mathrm{~g} \cdot \mathrm{mL}^{-1}, \mathrm{pH}$ of 5.1 , electrical conductivity (EC) of $0.64 \mathrm{mS} \cdot \mathrm{cm}^{-1}(1: 2.5$ suspension in water) and content of chloride and sodium of $553 \pm 7 \mathrm{mg} \cdot \mathrm{L}^{-1}$ and $290 \pm 63 \mathrm{mg} \cdot \mathrm{L}^{-1}$, respectively.

Three cherry tomato seedlings were planted on each grow bag, resulting in a planting density of 2.2 plants $\mathrm{m}^{-2}$. Tomato plants were trained to a support wire, around the grow table in a clockwise direction. Leaf axial suckers and old leaves were removed on a weekly basis according to commercial practice. To ensure proper fruit set, tomato plants were shaken at approximately midday on a daily basis. The tables were $1.0 \mathrm{~m}$ high from the ground. The tables were inclined to acquire a uniform slope, allowing the nutrient solution drained from the grow bags to be recollected back into the nutrient solution reservoir. In total, nine growing tables were used for the nine different treatments (Supplementary Figures S1 and S2). Each table was equipped with a reservoir tank where the nutrient solution was stored and the drained solution collected. Irrigation scheduling, frequency and duration were independent for each growing table and controlled through an irrigation controller (Rain Bird Corporation, Azusa, CA, USA). Irrigation was done through two $2 \mathrm{~L} \cdot \mathrm{h}^{-1}$ dripper stakes per plant.

During the growing period, four different nutrient solutions were employed to account for the different nutrient requirements of the plants depending on their growth stage (Supplementary Table S2). In addition, different levels of salinity were obtained by addition of $0 \mathrm{mM}, 17 \mathrm{mM}$, and $34 \mathrm{mM}$ of sodium chloride, resulting in nutrient solutions with an EC of approximately $2 \mathrm{mS} \cdot \mathrm{cm}^{-1}, 4 \mathrm{mS} \cdot \mathrm{cm}^{-1}$, and $5.7 \mathrm{mS} \cdot \mathrm{cm}^{-1}$, respectively. Chemicals used and preparation of the nutrient solution are shown in Supplementary Tables S3 and S4, respectively. The duration and frequency of irrigation for each substrate were calculated as described in chapter "Irrigation Scheduling" from the guide "Fertigation and Substrate Management in Closed Soilless Culture" by Pardossi, Carmassi [32]. The details of parameters used, calculation, and a number of irrigations are indicated in Supplementary Materials.

\subsection{Evaluation and Sample Preparation}

To measure the yield, tomatoes were harvested nearly every week from the 14 August 2017 until the 17 October 2017, resulting in a total of nine harvests. The yield was assessed by measuring the total weight and number of marketable fruits and the number of defective fruits, which included fruits that showed blossom end rot (BER) and fruit cracking. Each treatment (grow table) consisted of four replicates, were each replicate represented a total of three tomato plants in one grow bag, arranged in an unrandomized block design.

For sample preparation approximately $150 \mathrm{~g}$ of tomato fruit were cut in half and homogenised using an Ultra-Turrax T10 (IKA Works Inc., Wilmington, DE, USA). A part of the homogenate was stored at $-20{ }^{\circ} \mathrm{C}$ for later analysis of cations and dry matter content. The remaining homogenate was centrifuged for $5 \mathrm{~min}$ at $4000 \times \mathrm{g}$ and filtered through Miracloth (Calbiochem, San Diego, CA, USA). 


\subsection{Analysis of Quality Parameters, Minerals and Metabolites in Tomato Fruit Sap}

The dry matter of tomato fruits was determined by drying the tomato homogenate at $100{ }^{\circ} \mathrm{C}$ for approximately 2 days, until no further weight loss occurred.

For analysis of potassium, sodium, magnesium and calcium in tomato fruits the fresh homogenate was wet digested with acids and the elements subsequently quantified by ICP-OES analysis. For wet digestion, $13 \mathrm{~g}$ of fresh homogenate were weighed into a $100 \mathrm{~mL}$ volumetric flask. A $2 \mathrm{~mm}$ glass bead and $30 \mathrm{~mL}$ of a mixture consisting of $26.9 \mathrm{~mL}$ of $65 \%$ nitric acid and $3.1 \mathrm{~mL}$ of $70 \%$ perchloric acid were added. Wet digestion took place at approximately $150{ }^{\circ} \mathrm{C}$ on a hot plate until all solid particles had dissolved and the colour of the solution turned colourless. After cooling distilled water was added to the mark, the solution was filtered through ash-free filter paper and the cations analysed by ICP-OES using a Liberty RL instrument (Varian, Mulgrave, Australia). The wavelengths used for measurements were $769.896 \mathrm{~nm}$ for potassium, $589.592 \mathrm{~nm}$ for sodium, $279.553 \mathrm{~nm}$ for magnesium, and $317.933 \mathrm{~nm}$ for calcium [33].

The $\mathrm{pH}$ of the filtrated tomato sap was measured using a GE100 $\mathrm{pH}$ probe coupled to a GPHR 1400A pH meter (GHM Messtechnik GmbH, Regenstauf, Germany). The EC of the tomato sap was measured using a LF390-A/ST conductometer (WTW, Weilheim, Germany). Titratable acidity of the tomato sap was measured by adding $50 \mathrm{~mL}$ of deionised water to $20 \mathrm{~mL}$ tomato sap and titration with $0.05 \mathrm{~mol} \cdot \mathrm{L}^{-1} \mathrm{NaOH}$ to a $\mathrm{pH}$ of 8.0. For the following analyses the tomato sap was filtered through a $0.22 \mu \mathrm{m}$ nylon syringe filter. Total soluble solids (TSS) were measured with an Abbe refractometer (Carl Zeiss Jena GmbH, Jena, Germany) at $20^{\circ} \mathrm{C}$ and reported in Brix. Fructose, glucose, malic acid and citric acid were measured by HPLC as described previously [34]. The amino acids were quantified by HPLC through adaptation of a previously described method for quantification of glutamic acid and aspartic acid [10,35]. A detailed description for the quantification of amino acids can be found in the Supplementary Materials. Chloride was quantified by ion chromatography using a DX 500 system (Thermo Fisher Scientific, Waltham, MA, USA) equipped with an IonPac AG4A SC guard column and an AS4A SC $4 \times 250 \mathrm{~mm}$ analytical column and an ASRS suppressor column. The eluent consisted of $1.8 \mathrm{mM}$ sodium carbonate and $1.7 \mathrm{mM}$ sodium hydrogencarbonate and was set to a flow rate of $2 \mathrm{~mL} \cdot \mathrm{min}^{-1}$.

\subsection{Analysis of Leaves}

The leaf blade area was measured with a LI-3100C area meter (LI-COR Environmental, Lincoln, NE, USA), and the dry matter content was quantified by drying the leaf blades at $80^{\circ} \mathrm{C}$ until no further weight loss was observed. The dried leaves were ground to a fine powder for further analyses. For quantification of the chloride content $0.2 \mathrm{~g}$ of the leaf powder was weighed into a $50 \mathrm{~mL}$ volumetric flask and distilled water was added to the mark. After incubation for $60 \mathrm{~min}$ in an ultrasonic bath, the solution was filtered through a $0.22 \mu \mathrm{m}$ nylon syringe filter and analysed by ion chromatography as described above. For quantification of alkaline and earth alkaline metals, $0.3 \mathrm{~g}$ of the dried powder was weighed directly into $80 \mathrm{~mL}$ PFA digestion vessels (ACV vessels) and digested with a mixture of $3.5 \mathrm{~mL} 65 \%$ nitric acid and $2 \mathrm{~mL}$ of $30 \%$ hydrogen peroxide under a controlled pressure of 10 bar in a Mars 5 microwave oven (CEM, Kamp-Lintfort, Germany) for $50 \mathrm{~min}$. The digested solution was then transferred to a $50 \mathrm{~mL}$ volumetric flask topped with distilled water to the mark and analysed by ICP-OES as described above.

At the end of the experiment, the fresh and dry biomass of the whole plants was assessed. The fresh biomass of each tomato plant was measured by taking independently the fruit biomass and vegetative biomass. To measure the dry vegetative biomass, the plants were dried at $80^{\circ} \mathrm{C}$ until no further weight loss occurred.

\subsection{Statistics}

All statistical tests in this study were performed with IBM SPSS Statistics for Windows, Version 23.0. (IBM Corp., Armonk, NY, USA). Statistical tests were carried out on the following basis. Normal distribution of tested data was accepted based on either a 
Kolmogorov-Smirnov or Shapiro-Wilk test, where at the least the standardised residuals should exhibit normal distribution. In cases were the data was normally distributed a one factorial analysis of variance (one-way ANOVA) was carried out for the main factors (substrate and salinity) and single mean comparisons (treatment). If the Levene's test of equality of error variances was accepted, a Tukey HSD test was carried out for multiple comparisons. If the Levene's test of equality of error was not fulfilled, a Tamhane's T2 test was performed for multiple comparisons. If the data was not normally distributed, a Kruskal-Wallis one-way ANOVA nonparametric test was carried out. All statistical tests, and mean comparisons in this study were deemed significant at a probability level of less than $0.05(p<0.05)$. All grouped bar charts in this study were created with OriginPro 2018 (OriginLab, Northampton, MA, USA).

\section{Results}

To investigate the potential impact of sodium chloride concentrations typically observed in the groundwater of Malta on cherry tomato growth and quality, nutrient solutions were supplemented with sodium chloride at two levels, $17 \mathrm{mM}$ and $34 \mathrm{mM}$. The concentration of $17 \mathrm{mM}$ was selected since, according to the literature, salinity levels of 3 to $4 \mathrm{mS} \cdot \mathrm{cm}^{-1}$ (corresponding to 10 to $17 \mathrm{mM}$ sodium chloride) have only a small impact on the yield of round tomatoes [5]. In addition, in many sites of Malta, the chloride concentrations are in the range of 15 to $20 \mathrm{mM}$ (Figure 1). The concentration of $34 \mathrm{mM}$ sodium chloride was selected since it is close to the level of most contaminated sites in Malta. As a control nutrient solution without the addition of sodium chloride was used. In addition, plants were cultivated in the three most common substrates for tomato cultivation, Rockwool, perlite, and coco peat, to investigate whether the substrate can attenuate salinity stress. Thus, in total, nine conditions were tested, and for each condition, four replicates were performed.

\subsection{The Effect of Salinity on Fruit Weight of Cherry Tomato Grown in Different Substrates}

The accumulated fruit weight of harvests from 14 August 2017 to 17 October 2017 (in total, nine harvests) was recorded. In the control, plants grown in coco peat had the highest yield $\left(2.5 \pm 0.2 \mathrm{~kg} \cdot \mathrm{m}^{-2}\right)$, followed by those cultivated in Rockwool $\left(2.4 \pm 0.2 \mathrm{~kg} \cdot \mathrm{m}^{-2}\right)$ and perlite $\left(2.0 \pm 0.2 \mathrm{~kg} \cdot \mathrm{m}^{-2}\right)$ (Figure 2A). With a salinity of $17 \mathrm{mM} \mathrm{NaCl}$ in the nutrient solution, the yield decreased slightly. Coco peat $\left(2.2 \pm 0.3 \mathrm{~kg} \cdot \mathrm{m}^{-2}\right)$ retained the highest yield between the different substrates, followed by perlite $\left(1.9 \pm 0.3 \mathrm{~kg} \cdot \mathrm{m}^{-2}\right)$ and Rockwool $\left(1.7 \pm 0.2 \mathrm{~kg} \cdot \mathrm{m}^{-2}\right)$. A further decrease was noted at $34 \mathrm{mM}$ of $\mathrm{NaCl}$ in the nutrient solution with coco peat $\left(1.7 \pm 0.2 \mathrm{~kg} \cdot \mathrm{m}^{-2}\right)$ retaining the highest total yield amongst all substrates, followed by Rockwool $\left(1.6 \pm 0.2 \mathrm{~kg} \cdot \mathrm{m}^{-2}\right)$ and perlite $\left(1.4 \pm 0.3 \mathrm{~kg} \cdot \mathrm{m}^{-2}\right)$. Expressing the total yield loss as a percentage, at $17 \mathrm{mM}$ sodium chloride, the lowest yield loss was observed for perlite at $6.8 \%$, with coco peat being reasonably higher at $12.1 \%$ (Table 1 ). Yield loss was considerably higher in the case of Rockwool at $27.7 \%$. At $34 \mathrm{mM}$ sodium chloride, yield loss was pretty much similar at approximately $31 \%$ for all substrates. Expressing the yield loss as salinity yield decrease (SYD) per $1 \mathrm{mS} \cdot \mathrm{cm}^{-1}$ increase, SYD values ranged from 7.8 to $8.7 \%$ at a salinity of $34 \mathrm{mM} \mathrm{NaCl}$ in the nutrient solution.

The percentage of defective fruit (DF) from blossom end rot (BER) and fruit cracking ranged between $1.6 \%$ and $4.5 \%$. DF was lower in perlite compared to coco peat and Rockwool but remained unaffected by salinity (Figure 2D).

The average weight per fruit decreased slightly but significantly from approximately $14 \mathrm{~g}$ to $11 \mathrm{~g}$ with increasing salinity. No substantial differences were noted between the substrates (Figure 2B).

The number of fruits per $\mathrm{m}^{2}$ was the highest in the control treatment and tended to decrease with increasing salinity, with significant differences noted between the control and $34 \mathrm{mM}$ salinity. Using coco peat resulted in a higher number of fruits per $\mathrm{m}^{2}$ compared to perlite and Rockwool (Figure 2C). 
A

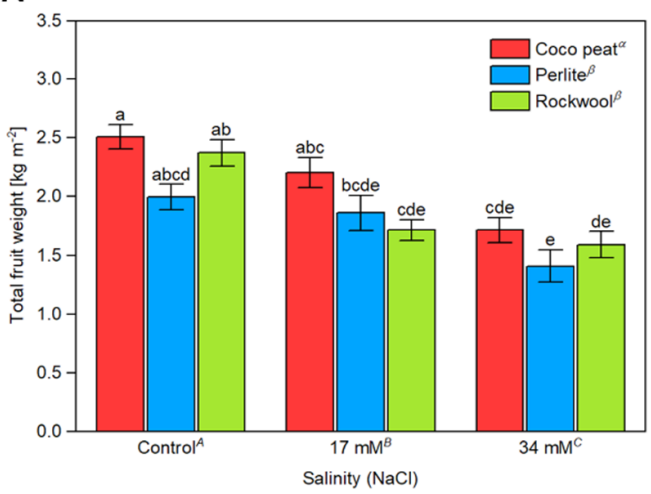

C

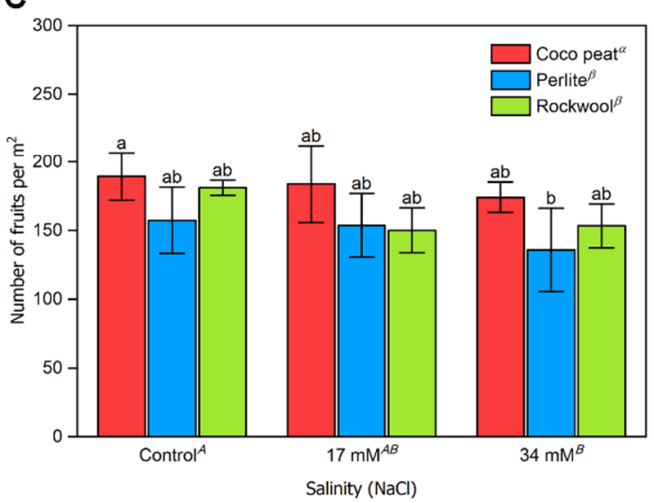

B

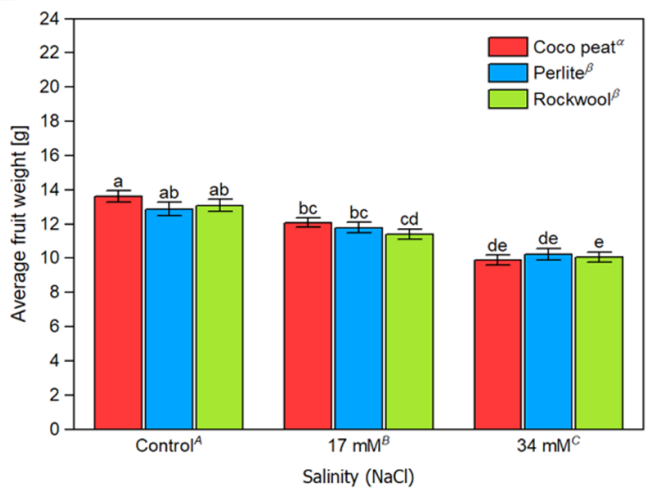

D

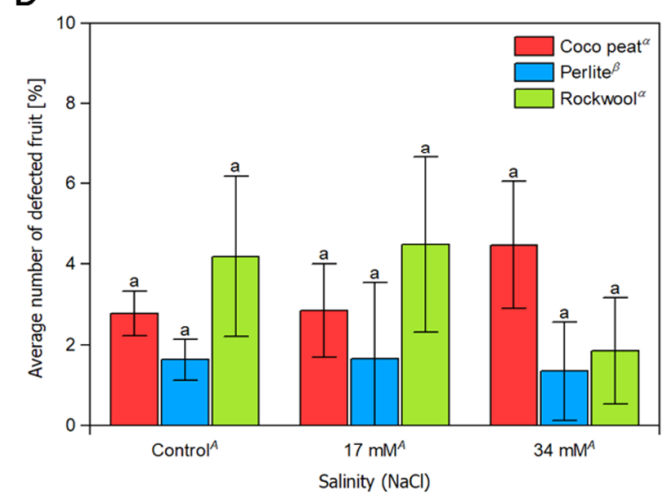

Figure 2. The yield of tomato cherry fruits, grown in different substrates with increasing salinity. The total fruit weight (A), average fruit weight (B), number of fruits per $\mathrm{m}^{2}(\mathbf{C})$ and average number of defective fruit (D) of tomato cherry fruits, grown in coco peat, perlite and Rockwool with increasing salinity by $\mathrm{NaCl}$ from nine harvests between 14 August and 17 October 2017. The error bars represent the SD. Upper-case letters compare the salinity treatments, Greek letters compare different substrates, lower-case letters within the graph compare single mean values of the treatments. The raw data are available in Supplementary File S1.

Table 1. Yield loss and salinity yield decrease (SYD) for cherry tomatoes grown in different substrates and salinity.

\begin{tabular}{|c|c|c|c|c|c|c|}
\hline \multirow{2}{*}{$\begin{array}{c}\mathrm{NaCl} \\
\mathrm{mM}\end{array}$} & \multicolumn{2}{|c|}{ Coco Peat ${ }^{a}$} & \multicolumn{2}{|c|}{ Perlite $^{a}$} & \multicolumn{2}{|c|}{ Rockwool $^{\text {a }}$} \\
\hline & $\begin{array}{c}\text { Yield Loss } \\
\%\end{array}$ & $\begin{array}{c}\text { SYD } \\
\% \mathrm{mS} \cdot \mathrm{cm}^{-1}\end{array}$ & $\begin{array}{c}\text { Yield Loss } \\
\%\end{array}$ & $\begin{array}{c}\text { SYD } \\
\% \mathrm{mS} \cdot \mathrm{cm}^{-1}\end{array}$ & $\begin{array}{c}\text { Yield Loss } \\
\%\end{array}$ & $\begin{array}{c}\text { SYD } \\
\% \mathrm{mS} \cdot \mathrm{cm}^{-1}\end{array}$ \\
\hline 0 & 0 & 0 & 0 & 0 & 0 & 0 \\
\hline 17 & 12.1 & 6.1 & 6.8 & 3.4 & 27.7 & 13.8 \\
\hline 34 & 31.6 & 8.3 & 29.5 & 7.8 & 32.9 & 8.7 \\
\hline
\end{tabular}

a The data are based on nine harvests between 14 August and 17 October 2017.

\subsection{Effects of Salinity and Growth Substrates on Cherry Tomato Fruit Quality}

The dry matter content and the total soluble solids (TSS) are important criteria for tomato fruit quality $[31,36]$. As indicated in Figure 3A,B, both increased significantly with the salinity level. Averaged on the salinity levels, both parameters were higher in coco peat than in Rockwool and perlite but the differences were more obvious in the presence of $34 \mathrm{mM}$ sodium chloride. The $\mathrm{pH}$ of the tomato sap decreased significantly with increasing salinity in the nutrient solution, with no significant differences noted amongst different substrates (Figure 3C). However, the decrease was small and even between the control and the nutrient solution containing $34 \mathrm{mM}$ sodium chloride only a difference of approximately $0.1 \mathrm{pH}$ unit was observed. The decreased $\mathrm{pH}$ was accompanied by a slight but significant increase in titratable acidity from $75 \mathrm{mM}$ to $78 \mathrm{mM}$ in the control treatment and increased 
to $84 \mathrm{mM}$ to $87 \mathrm{mM}$ at $34 \mathrm{mM}$ sodium chloride (Figure 3D). Again, there were no significant differences between the substrates.

A

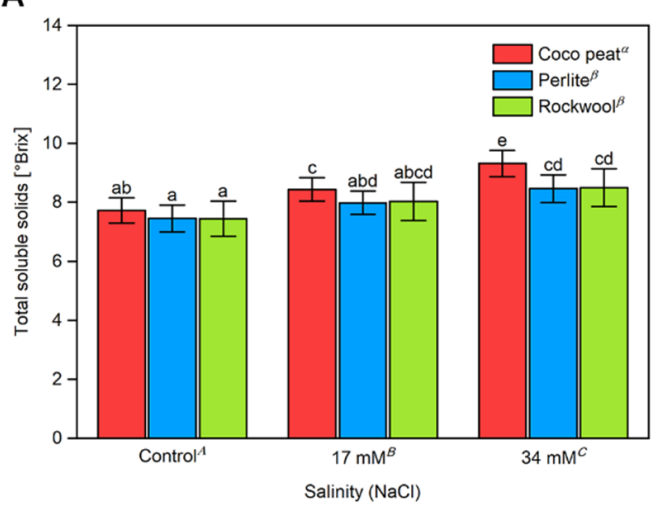

C

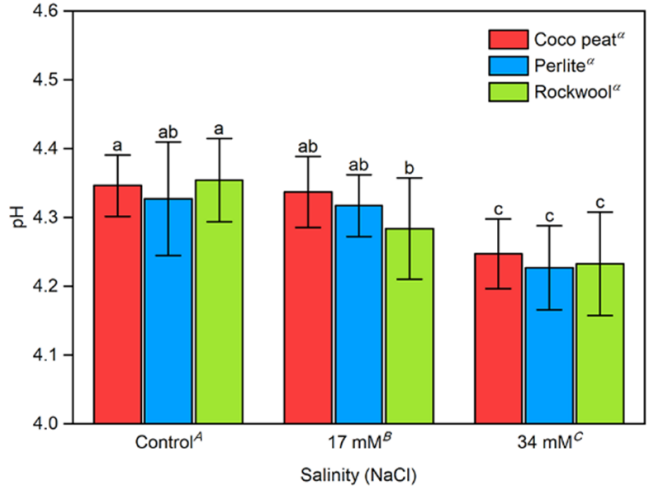

B

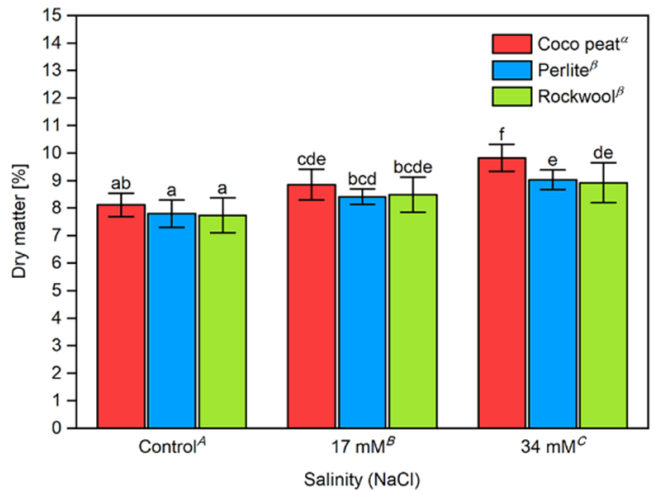

D

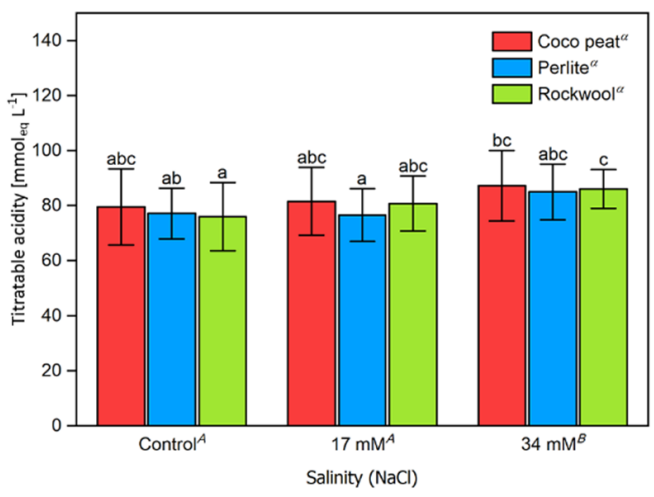

Figure 3. The total soluble solids content, titratable acidity and dry matter content of cherry tomato fruit grown in different substrates with increasing salinity. The average total solids content (A), dry matter content (B), $\mathrm{pH}(\mathbf{C})$ and titratable acidity (D) from five harvests between the 4 September and 17 October 2017 grown in coco peat, perlite and Rockwool at a sodium chloride content of 0,17 and $34 \mathrm{mM}$ in the nutrient solution. The mean and SD of the total soluble solids were calculated from four different grow bags on each grow table. Upper-case letters compare the salinity treatments; Greek letters compare different substrates, lower-case letters within the graph compare single mean values of the treatments. The raw data are available in Supplementary File S1.

\subsection{Metabolite Content of Cherry Tomato Fruits Cultivated in the Presence of Sodium Chloride}

To this end our data indicated that the total soluble solids and the titratable acidity increased with the sodium chloride concentration in the growth medium, which in agreement with previous reports about round [15,21] and cherry tomatoes [16]. However, little is known about responses of specific metabolites in cherry tomato fruits upon high salt present in the nutrient solution. Thus, we analysed the sugar profile, organic acids, and amino acids. The latter is particularly important since changes in the amino acid composition during ripening are known to be crucial for the taste of ripe tomatoes.

Fructose and glucose are the main sugars of cultivated tomatoes, with fructose generally being slightly more abundant than glucose [31]. Indeed, cherry tomatoes investigated here showed that profile (Figure 4A,B). Similar to the results for total soluble solids, both sugars increased with the sodium chloride concentration. However, the ratio of both sugars remained constant. Significant differences in the amount of both sugars between the substrates were only noted between coco peat and perlite, although within each salinity level, no significant differences were found with different substrates. 
A

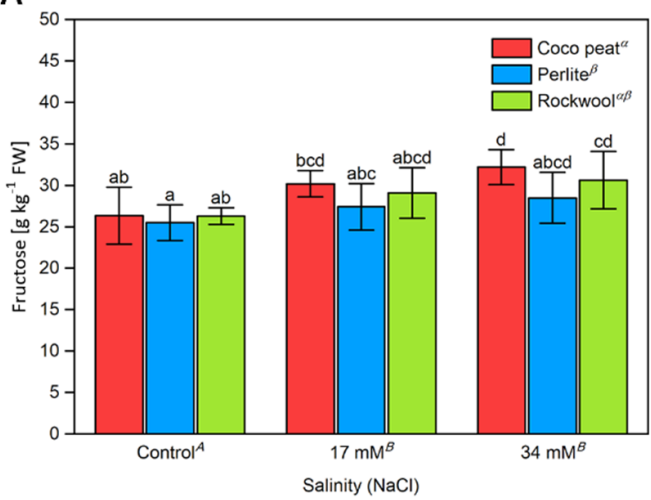

C

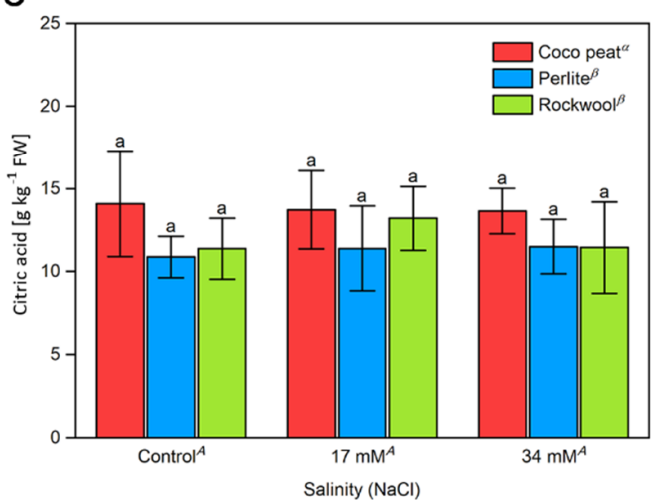

B

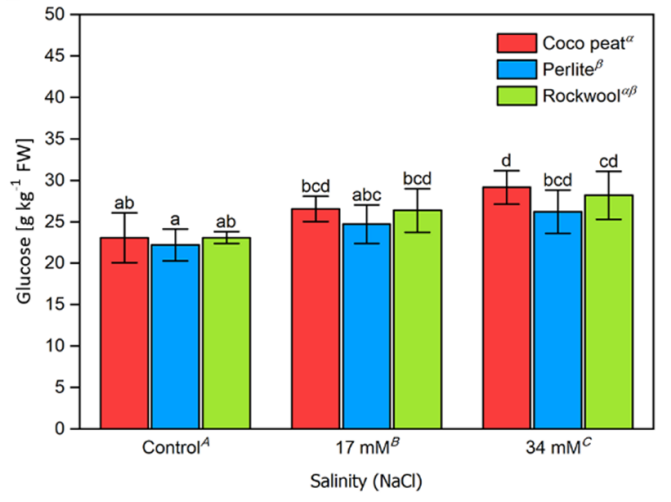

D

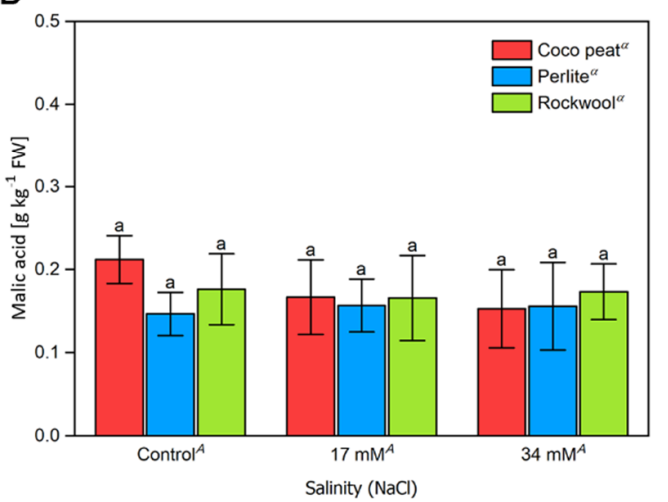

Figure 4. The sugar content and acidity of cherry tomato fruit grown in different substrates with increasing salinity. The fructose (A), glucose (B), citric acid (C), and malic acid (D) content of cherry tomato fruits from two harvests between the 10 October and 17 October 2017 grown in coco peat, perlite and Rockwool with increasing salinity by sodium chloride in the nutrient solution. The error bars represent the SD. Upper-case letters compare the salinity treatments, Greek letters compare different substrates, lower-case letters within the graph compare single mean values of the treatments. The raw data are available in Supplementary File S1.

For citric acid and malic acid no statistically significant differences were noted, neither for different substrates nor for different levels of salinity (Figure 4C,D). Only averaged on the salinity levels, the citric acid concentration in coco peat was somewhat higher than in the other substrates. This is in contrast to the results for titratable acidity. However, it must be noted that analysis of organic acids by HPLC measures the total concentration while titration with sodium hydroxide measures the amount of protons to be neutralised. In addition, we observed huge variation between samples for these two parameters, impeding reliable detection of small differences under different treatments.

Tomato is a fruit that contains high levels of free amino acids. In unripe fruits, glutamine and $\gamma$-aminobutyric acid are the most abundant amino acids. During ripening, their concentration declines while free glutamic acid reaches extremely high concentrations of up to $5 \mathrm{~g} \cdot \mathrm{L}^{-1}[9,10,37]$, which is important for the characteristic taste of tomatoes. In contrast, the concentration of aspartic acid has been shown to remain constant during ripening [10]. Quantification of free amino acids revealed that the glutamic acid content was independent of the salt concentration and the type of growth substrate (Figure 5A). In contrast, glutamine, aspartic acid and asparagine decreased slightly with increasing salinity, though significant differences could only be seen at the scale of the whole experiments (Figure 5B-D). The proline content of cherry tomato fruits increased strongly in all substrates with increasing salinity (Figure 5E). Significant differences in the proline content between substrates were also noted. The proline content of fruits was significantly higher in coco peat than on perlite grown plants. The differences were most obvious at $34 \mathrm{mM}$ sodium chloride with the proline concentration in perlite being only about $60-70 \%$ 
compared to that of coco peat and Rockwool. No major differences could be observed for the other proteinogenic amino acids (Supplementary Table S5).

A

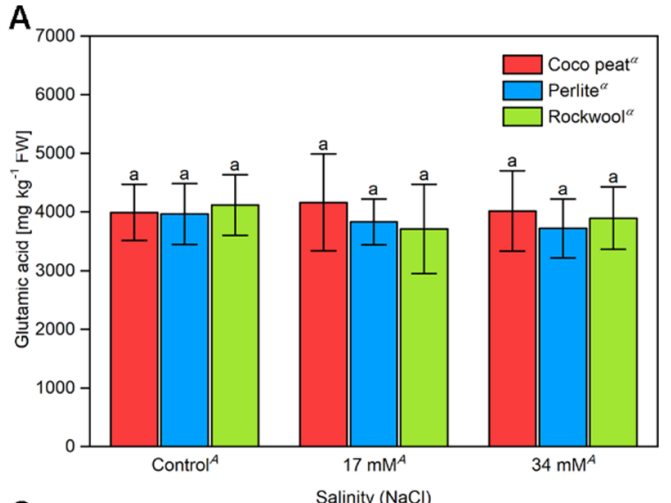

C

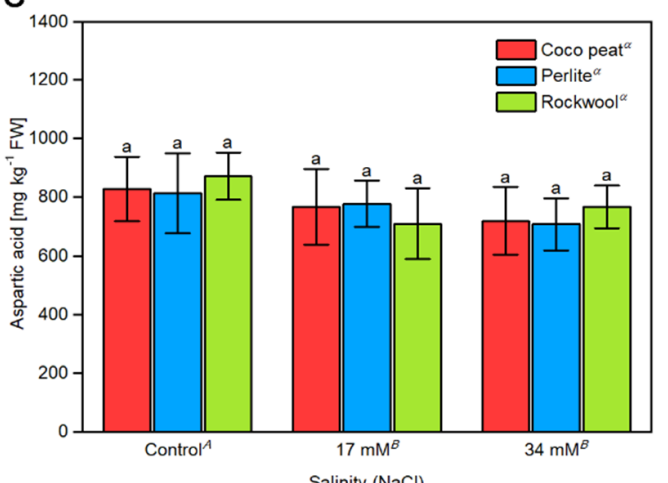

$E$

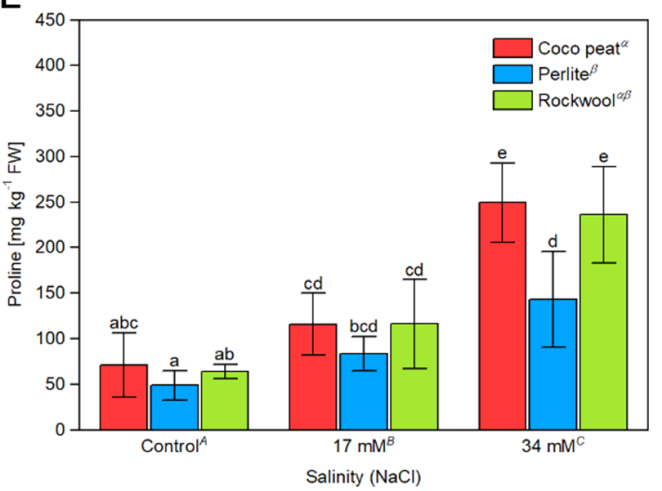

B

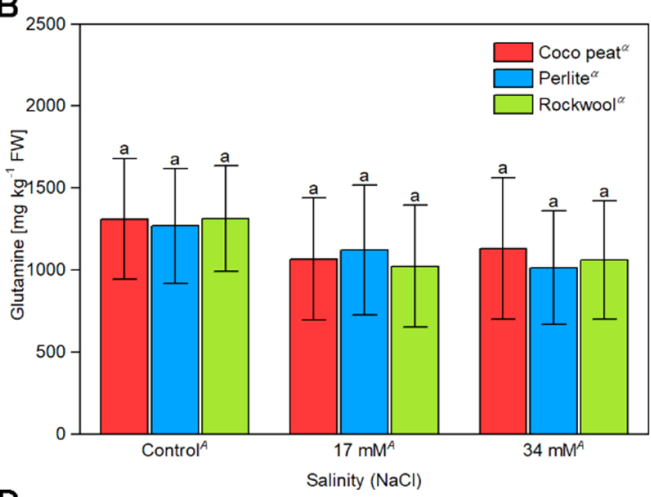

D

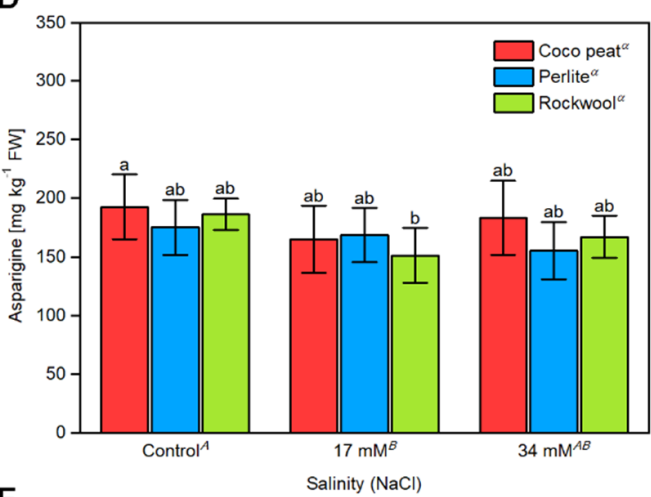

$\mathrm{F}$

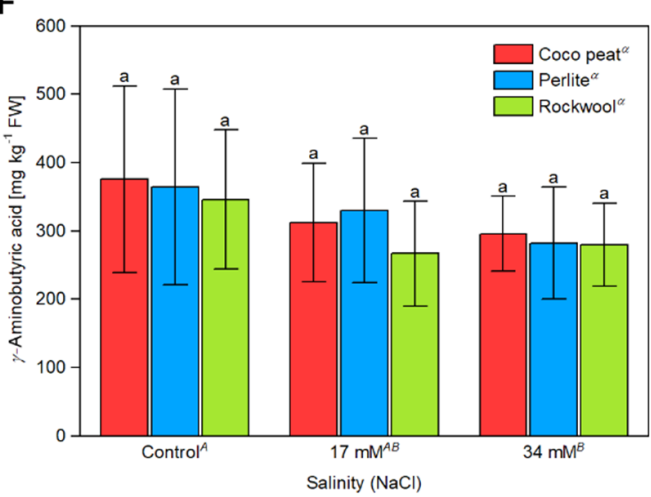

Figure 5. The content of free amino acids present in cherry tomato fruit grown in different substrates and salinity levels. The (A) glutamic acid, (B) glutamine, (C) aspartic acid, (D) asparagine, (E) proline and (F) $\gamma$-aminobutyric acid content of cherry tomato fruits from two harvests the 10th of September and 17th of October 2017 grown in coco peat, perlite and Rockwool under different levels of salinity in the nutrient solution. The error bars represent the SD. Upper-case letters compare the salinity treatments, Greek letters compare different substrates, lower-case letters within the graph compare single mean values of the treatments. The raw data are available in Supplementary File S1.

Previously, it was reported that the non-proteinogenic amino acid $\gamma$-aminobutyric acid (GABA) increases in the presence of salt in tomato fruits [22]. However, we could not detect such a response. In our experiment, the level of $\gamma$-aminobutyric acid was largely unaffected by the growth substrate and rather decreased with increasing salinity level (Figure 5F).

\subsection{Impact of Salinity on Nutrient Balance and Growth Performance of Shoots}

Salinity has been reported to affect shoots in multiple ways. High levels of sodium chloride were shown to induce nutritional imbalance, particularly by reducing the content of potassium $[23,25]$ but also of other minerals including calcium [24], phosphorus and 
copper [23] while the levels of sodium and chloride ions increase clearly [24]. At the phenotypic level salt stress was reported to reduce the biomass [23].

To investigate the impact of salinity on the vegetative tissue the content of minerals in leaves was analysed by ICP-OES and ion chromatography. As expected, the chloride content of young tomato leaves increased significantly with the salinity of the nutrient solution from about $10 \mathrm{mg} \cdot \mathrm{g}^{-1} \mathrm{DM}$ to $21-27 \mathrm{mg} \cdot \mathrm{g}^{-1} \mathrm{DM}$ at $17 \mathrm{mM}$ sodium chloride depending on the substrate (Figure 6A). Interestingly, at a salinity of $34 \mathrm{mM}$ in the nutrient solution tomato leaves from plants grown in the perlite $\left(28 \mathrm{mg} \cdot \mathrm{g}^{-1} \mathrm{DM}\right)$ substrate, had a significantly lower chloride content than those grown in Rockwool (39 mg.g $\left.{ }^{-1} \mathrm{DM}\right)$ and coco peat $\left(42 \mathrm{mg} \cdot \mathrm{g}^{-1} \mathrm{DM}\right)$. The same trend was also seen for sodium ions (Figure $6 \mathrm{~B}$ ).

A

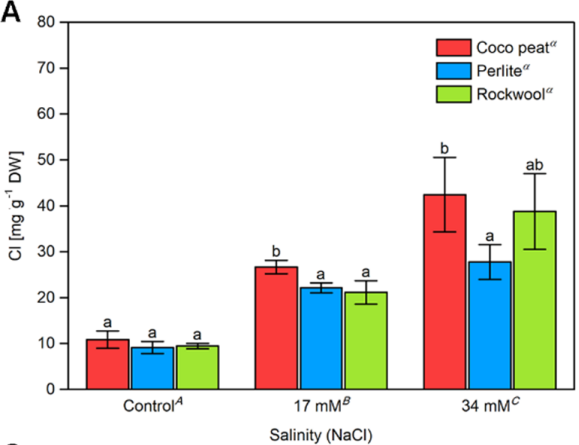

C

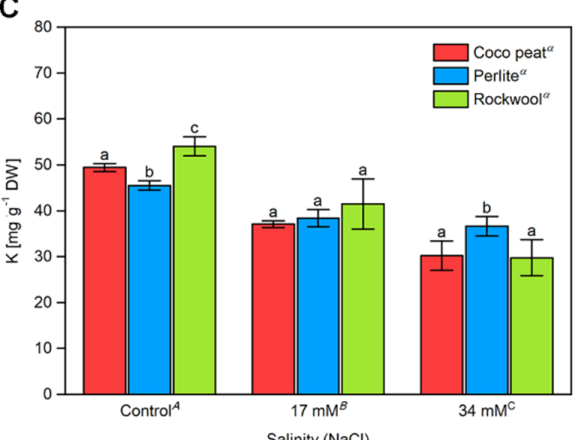

E

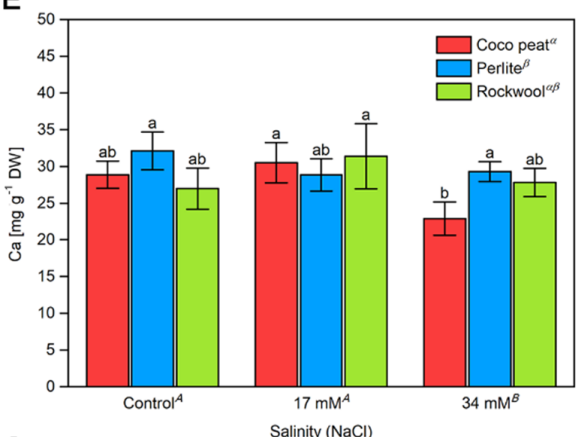

G

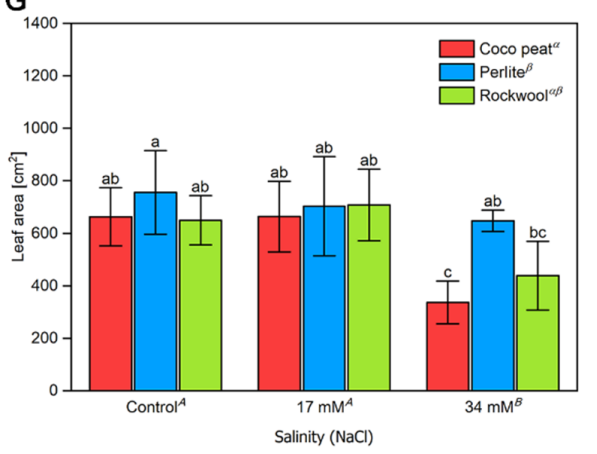

B

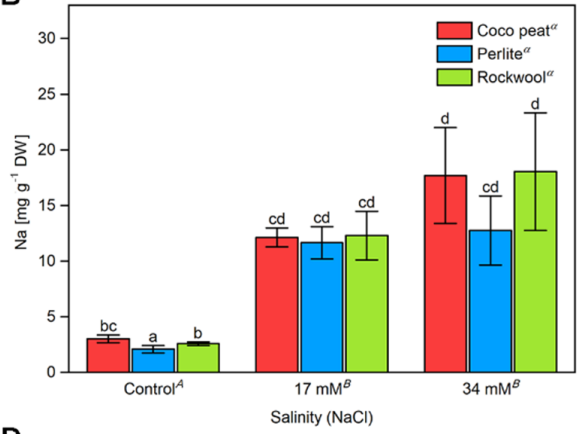

$\mathrm{D}$

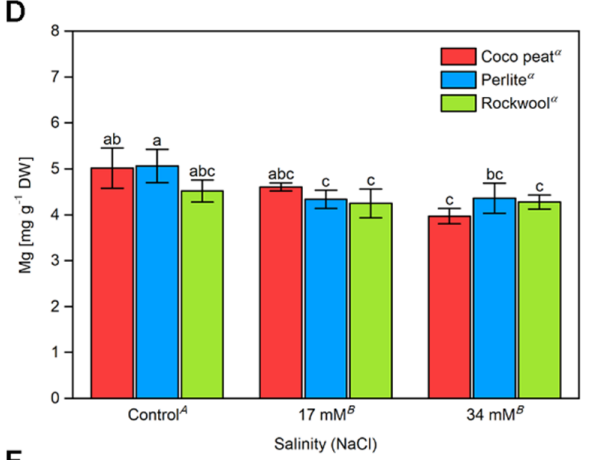

$F$

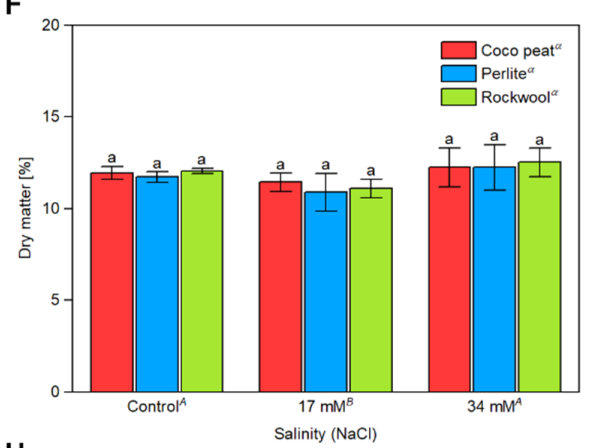

$\mathrm{H}$

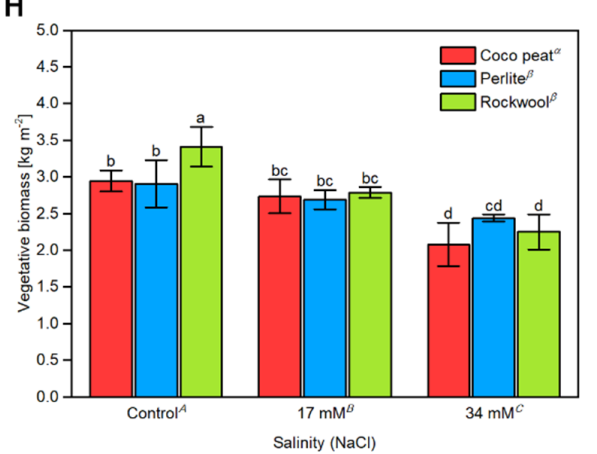

Figure 6. Ion composition, dry matter content, leaf area, and vegetative biomass of tomato plants 
with increasing salinity. The chloride (A), sodium (B), potassium (C), magnesium (D) and calcium (E) content of young tomato leaves grown in different substrates with increasing salinity were sampled on 19 October 2017. From the same sample the dry matter (F) and leaf area (G) was assessed. The vegetative biomass $(\mathbf{H})$ was assessed at the end of the experiment. The error bars represent the SD. Statistical comparison of mean values between substrates was calculated for each salinity level separately. Upper-case letters compare the salinity treatments; Greek letters compare different substrates, lower-case letters within the graph compare single mean values, within each salinity level separately. The raw data are available in Supplementary File S1.

With an increasing sodium chloride concentration in the nutrient solution, the overall potassium content of tomato leaves decreased significantly. In the control treatment, the leaf potassium content was the highest with Rockwool $\left(54 \mathrm{mg} \cdot \mathrm{g}^{-1} \mathrm{DM}\right)$, followed by coco peat $\left(49 \mathrm{mg} \cdot \mathrm{g}^{-1} \mathrm{DM}\right)$ and perlite $\left(46 \mathrm{mg} \cdot \mathrm{g}^{-1} \mathrm{DM}\right)$. At a concentration of $17 \mathrm{mM}$ sodium chloride in the nutrient solution, the potassium content dropped to $37-42 \mathrm{mg} \cdot \mathrm{g}^{-1} \mathrm{DM}$ and at $34 \mathrm{mM}$ sodium chloride to $30-37 \mathrm{mg} \cdot \mathrm{g}^{-1} \mathrm{DM}$. Interestingly again, at the highest salinity level tested, $34 \mathrm{mM}$ sodium chloride, leaves from tomato plants grown in perlite had a significantly higher potassium content $\left(37 \mathrm{mg} \cdot \mathrm{g}^{-1} \mathrm{DM}\right)$, than those obtained from coco peat and Rockwool with about $30 \mathrm{mg} \cdot \mathrm{g}^{-1} \mathrm{DM}$, respectively (Figure 6C). Lowered leaf potassium contents as one factor of the salinity induced fruit yield reduction are in agreement with findings that potassium contents higher than $38 \mathrm{mg} \cdot \mathrm{g}^{-1}$ leaf DM are necessary for high fruit yield [38]. The contents of magnesium decreased significantly with the salinity from approximately $5.0 \mathrm{mg} \cdot \mathrm{g}^{-1} \mathrm{DM}$ in the control to approximately $4.5 \mathrm{mg} \cdot \mathrm{g}^{-1}$ $\mathrm{DM}$ and $4.2 \mathrm{mg} \cdot \mathrm{g}^{-1} \mathrm{DW}$ at $17 \mathrm{mM}$ and $34 \mathrm{mM}$ sodium chloride, respectively. The type of substrate had no significant effect on the magnesium content. For calcium no clear trend was visible and its content remained essentially unaffected by the salinity levels investigated (Figure 6E).

No significant difference in the leaf dry matter content was noted amongst plants grown in different substrates (Figure 6F) while a strong decline of the area of a fully developed leaves was observed, particularly at $34 \mathrm{mM}$ sodium chloride (Figure 6G). The total vegetative biomass was assessed at the end of the experiment, and a clear reduction from approximately $3 \mathrm{~kg} \cdot \mathrm{m}^{-2}$ for the control to $2.7 \mathrm{~kg} \cdot \mathrm{m}^{-2}$ at $17 \mathrm{mM}$ sodium chloride and approximately $2.2 \mathrm{~kg} \cdot \mathrm{m}^{-2}$ at $34 \mathrm{mM}$ sodium chloride was observed (Figure $6 \mathrm{H}$ ). The type of substrate had a comparatively small effect on that parameter.

\subsection{Mineral Composition of Tomato Fruits}

While the mineral and sodium chloride content of leaves is highly relevant for growth performance, alteration of minerals in fruits may affect the quality. However, minerals in tomato fruits cultivated under salt stress have been rarely assessed, particularly in cherry tomatoes.

A significant but small increase in EC was observed (Figure 7A). Amongst all salinity treatments the EC in coco peat was approximately $0.5 \mathrm{mS} \cdot \mathrm{cm}^{-1}$ higher than in Rockwool or perlite. Similar to leaves, a clear increase of the chloride (Figure 7B) and sodium (Figure 7C) content of tomato fruits was seen. Again, the highest contents for these ions were observed in fruits of plants cultivated in coco peats. The reason for that is not entirely clear. In contrast to leaves, where potassium declined considerably with increasing sodium chloride concentrations, only a very small decrease of this cation was observed and its content remained in all treatments between approximately 3500 and $3800 \mathrm{mg} \cdot \mathrm{kg}^{-1}$ FW (Figure 7C). For calcium, a slight increase from approximately $50 \mathrm{mg} \cdot \mathrm{kg}^{-1} \mathrm{FW}$ to approximately $60 \mathrm{mg} \cdot \mathrm{kg}^{-1} \mathrm{FW}$ was observed while the content of magnesium decreased very slightly for fruits of plants grown on Rockwool or perlite while such a trend could not be seen for coco peat, where the magnesium content remained unchanged. 
A
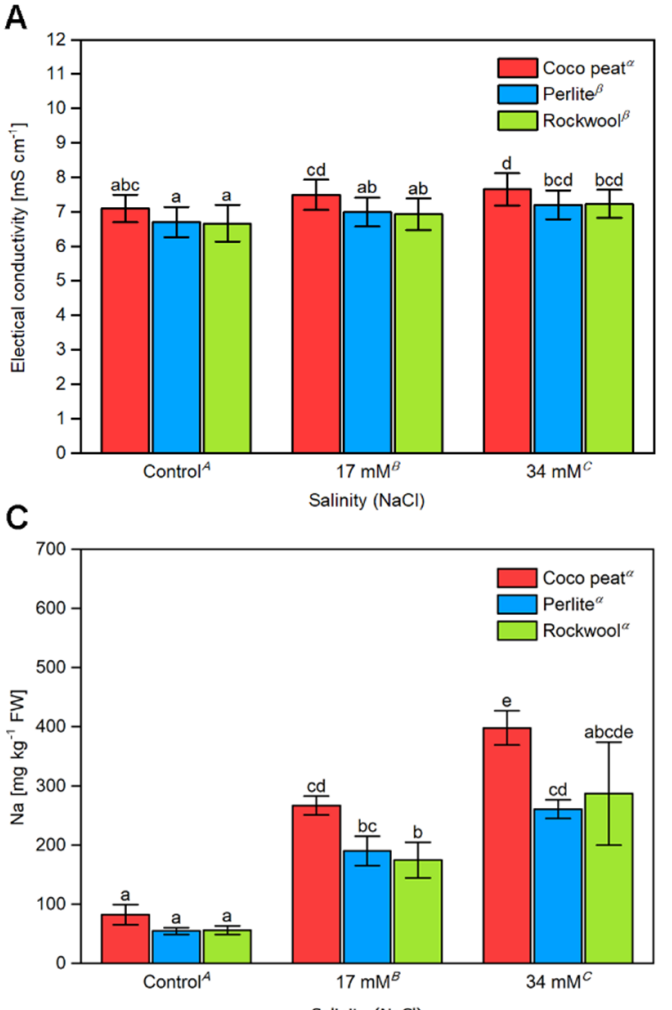

E

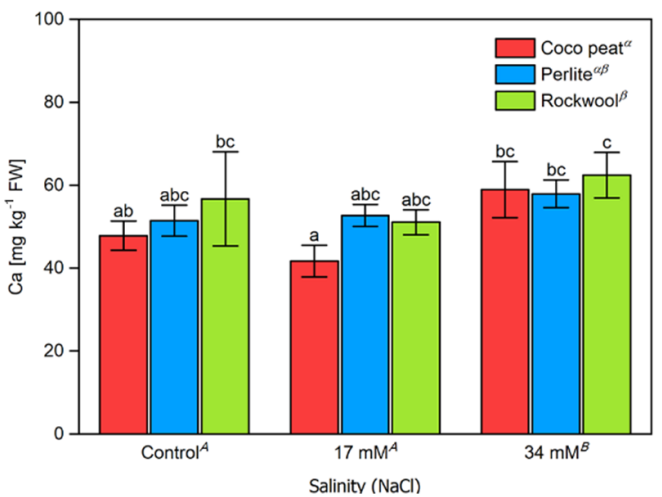

B

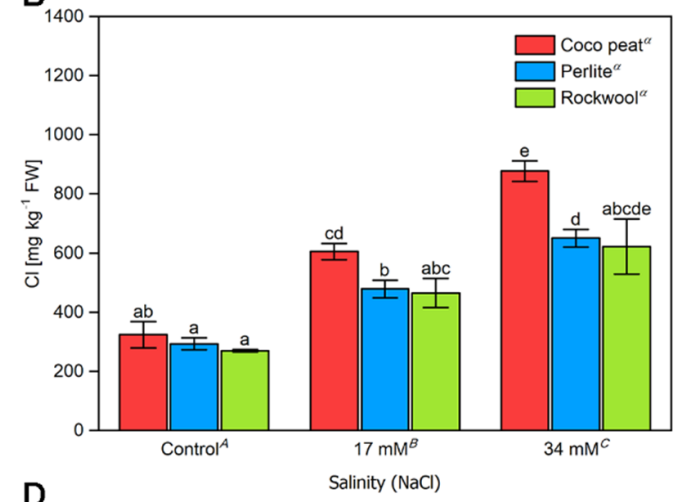

D

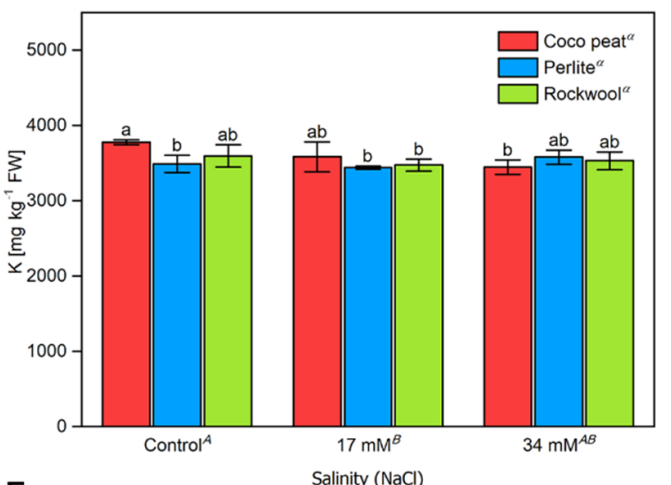

$\mathbf{F}$

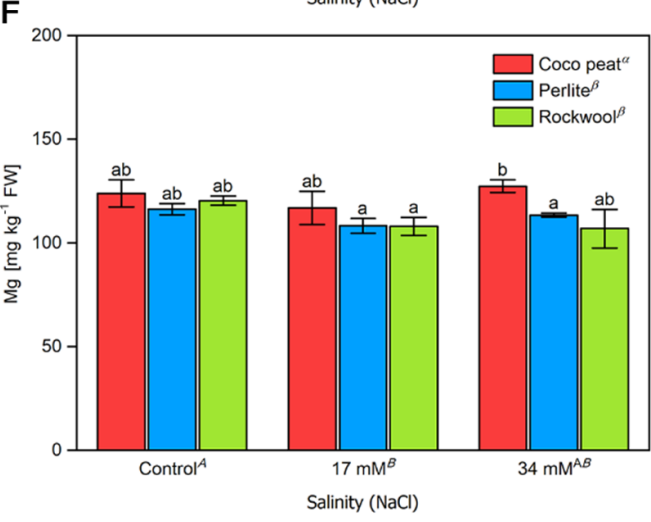

Figure 7. The electrical conductivity and mineral composition of cherry tomato fruit grown in different substrates with increasing salinity. The electrical conductivity (A) from 5 harvests between the 4 September 2017 and 17 October 2017. The chloride (B), sodium (C), potassium (D), calcium (E), and magnesium (F) content of cherry tomato fruits from the 11 September 2017 and 10 October 2017 grown in coco peat, perlite and Rockwool with increasing salinity by $\mathrm{NaCl}$ in the nutrient solution. The error bars represent the SD. Upper-case letters compare the salinity treatments; Greek letters compare different substrates, lower-case letters within the graph compare single mean values of the treatments. The raw data are available in Supplementary File S1.

These results show that the content of chloride and sodium increases clearly in fruits of plants grown in a medium containing sodium chloride. In contrast, the contents of potassium, calcium, and magnesium were only minimally affected. Rockwool and perlite behaved very similarly while fruits of plants grown in coco peat accumulated more chloride and sodium, which is likely also the reason for the increased EC. However, it is worthy to note that the highest yield was obtained on coco peat-grown plants. 


\section{Discussion}

Soil salinization is an increasing problem for plant cultivation in arid climates. Growing plants in hydroponic systems is an alternative to conventional farming of vegetables and has a number of advantages like minimising problems with soil-borne pathogens and independency of soil quality. However, particularly at islands, the available water can contain considerable concentrations of salts since the aquifers may be in contact with the sea. For instance, in Malta the levels for chloride and sodium reach in many sites $10 \mathrm{mM}$ and exceed in some sites even $20 \mathrm{mM}$ (Figure 1). Nutrient solutions prepared with such water contain a significant amount of sodium chloride, which may impact plant growth. For tomatoes, the economically most important vegetable, the presence of sodium chloride in the nutrient solution is known to reduce yield [5] but may increase fruit quality, particularly the level of soluble sugars, which may help to compensate for increased osmotic pressure caused by the salt. Cherry tomato fruits contain higher levels of glucose and fructose even in the absence of salt stress. Cultivation of cherry tomatoes is interesting from the economical point of view since they have a higher market value than conventional round tomatoes. Here, we investigated how presence of salt in nutrient solutions at concentrations frequently found in the groundwater in Malta impacts on yield, quality and physiology of cherry tomato fruits. To simulate contamination with salt, sodium chloride was added to the nutrient solutions at levels of $17 \mathrm{mM}$ and $34 \mathrm{mM}$ to simulate high and very high salt contents in the groundwater, respectively. For the experiments the cherry tomato cultivar Solanum lycopersicum cv. Gustafano was used. In addition, the performance of the plants in different growth substrates, including coco peat, perlite and Rockwool, was investigated.

Our data show that the yield was clearly negatively affected by presence of salt in the medium (Figure 2). To compare the data with previous results, the salinity yield decrease (SYD) in \% yield loss per $\mathrm{mS} \cdot \mathrm{cm}^{-1}$ was calculated, which was in the range of $8 \%$ per $\mathrm{mS} \cdot \mathrm{cm}^{-1}$ (Table 1). This is very similar to values found in previous studies for round tomatoes, which ranged from approximately 5 to $10 \%$ per $\mathrm{mS} \cdot \mathrm{cm}^{-1}[20,39]$. The impact of the substrate was comparatively small. The smallest percentage decline was seen in perlite but it must be emphasised that the yield with this substrate was lowest in all conditions. Decreases in the average fruit weight were noted at increased salinity, which is in agreement with previous reports $[20,39,40]$. In the control, the average fruit weight was $13.2 \pm 3.7 \mathrm{~g}$ while it dropped to $11.8 \pm 3.0 \mathrm{~g}$ and $10.1 \pm 3.0 \mathrm{~g}$ at $17 \mathrm{mM}$ and $34 \mathrm{mM}$ sodium chloride, respectively. While the total weight of fruits and the average weight per fruit dropped significantly, the effect of high salinity on the number of fruits was low. Interestingly, while the percentage of blossom end rot was reported to increase with sodium chloride-induced salinity [20] we could not observe a statistically significant increase of blossom end rot in our experiments (Figure 2D). However, this is in agreement with the observation that the fruit calcium concentration was kept also at higher salinity levels (Figure 7E).

While there was a clear reduction in yield, the fruit quality of tomato fruit was enhanced with increasing salinity. The total soluble solids (Figure 3A), which is related the total dry matter (Figure 3B) increased significantly with the salinity. Accordingly, also the contents of glucose and fructose increased in the same way (Figure $4 \mathrm{~A}, \mathrm{~B}$ ) while the ratio of fructose and glucose remained equal. Interestingly, the highest total soluble solids and sugar contents were under all conditions observed in plants grown in coco peat. Differences between the total soluble solids of tomato fruits when grown in coco peat in comparison to Rockwool have been previously reported [7]. This suggests that the substrate type might impact the amount of total soluble solids in tomato fruits.

The acidity of tomato cherry fruits also increased significantly with increasing salinity in the nutrient solution, which resulted in a slightly but significantly lower $\mathrm{pH}$ of the fruits as well as in an increased titratable acidity (Figure 3C,D), which is in agreement with previous results from round tomatoes $[14,20,21]$. In contrast, the content of citric acid and malic acid (Figure 4C,D) remained equal or dropped slightly. This shows that the total amount of citric acid and malic acid were not responsible for increased acidity and indicates that the contents of the counter cations (metal ions, amines etc.) might decline. Indeed, 
quantification of minerals in tomato fruits indicated that the level of chloride reached higher molarity than of sodium (Figure 7B,C) while the level of potassium declined concomitantly (Figure 7D). This indicates that the ratio of metal ions and counter anions gets imbalanced, which may be responsible for the lower $\mathrm{pH}$ and increased titratable acidity while the contents of citric acid and malic acids were essentially unaffected. Amongst the different substrates no significant differences were noted for $\mathrm{pH}$, titratable acidity, citric acid and malic acid content, showing that substrate has little or no impact on these parameters in cherry tomato fruit, which corresponds with pervious results from round tomatoes $[7,41]$.

The amino acid glutamic acid is in its free form an important factor for the typical taste of tomato fruit. Thus, a potential effect of salinity on its level was of particular interest. However, our data showed that the presence of sodium chloride up to a concentration of $34 \mathrm{mM}$ in the nutrient solution had no significant impact on the content of glutamic acid (Figure 5A). The same also accounted for its precursor, glutamine, and the closely related amino acids aspartic acid and asparagine (Figure 5B-D). With the exception of proline, the levels of the other proteinogenic amino acids were not significantly affected by salinity. This result was surprising since an increase in the total concentration of free amino acids has been reported for tomato fruits cultivated under high salinity [37,42].

However, in the study of Zushi and Matsuzoe salinity was elevated by increasing the concentration of the main nutrients [42], which also increases the level of nitrogen sources and may thereby stimulate the biosynthesis of amino acids. In the study of Yin et al., 2010 [37] a much higher sodium chloride concentration of $160 \mathrm{mM}$ was applied after the start of flowering. In addition, the variety 'Micro Tom' was used, which is frequently used in research but unsuitable for production of tomatoes for human consumption. In addition, 'Micro Tom' contains sugars, organic acids and amino acids at levels highly distinct from that observed in varieties used for the production of tomatoes for human consumption. For instance, while glutamate increases significantly during ripening and reaches levels of more than $3000 \mathrm{mg} \cdot \mathrm{kg}^{-1} \mathrm{FW}$ in ripe fruits [10], in 'Micro Tom' glutamate levels did not increase during ripening and remained at less than $900 \mathrm{mg} \cdot \mathrm{kg}^{-1} \mathrm{FW}$ at any stage [37]. Moreover, the glutamate levels were in 'Micro Tom' even in red fruits lower than that of glutamine. The special physiology of 'Micro Tom' and the different experimental settings might explain the different results for accumulation of the proteinogenic amino acids and may also account for different results for accumulation of the non-proteinogenic amino acid $\gamma$-aminobutyric acid (GABA). In 'Micro Tom' GABA was reported to increase upon salt stress [37].

In our experiment, no statistically significant results could be observed for GABA in fruits cultivated in the presence of sodium chloride and the control. The only amino acid that significantly increased in cherry tomato fruit with increasing salinity was proline (Figure 5E). Proline is considered as an osmolyte, which upon osmotic stress, for instance caused by drought or high salinity, proline is accumulated to balance the osmotic potential in plant cells [43]. Proline accumulation has also been reported for 'Micro Tom' under salt stress [37]. Interestingly, tomato fruits grown in coco peat and Rockwool had a higher proline content than such grown in perlite, particularly in presence of sodium chloride (Figure 5E). This indicates that the perlite grown plants experienced less salt stress compared to that grown in coco peat or Rockwool. A possible explanation might be the twice as high irrigation rate required for perlite (Supplementary Materials), which might prevent build-up of high salt concentrations in the root zone during phases of intensive evapotranspiration. However, it is important to note that coco peat and Rockwool performed equal or, though not significantly, better than perlite with respect to yield (Figure 2A).

The electrical conductivity of tomato cherry fruit sap increased with the salinity, indicating the presence of more ions. Interestingly, tomato fruits grown in coco peat had a higher electrical conductivity (approximately $0.5 \mathrm{mS} \cdot \mathrm{cm}^{-1}$ higher) in their tomato sap in comparison to plants grown in Rockwool and perlite (Figure 7A). The increased electrical conductivity may be partly explained by the increased contents of sodium and chloride ions in the fruits (Figure $7 \mathrm{~B}, \mathrm{C}$ ). Higher chloride and sodium concentrations in tomato 
fruits grown under high salinity were expected and similar results have been reported previously $[44,45]$. Interestingly, the chloride as well as the sodium content of tomato fruits grown in coco peat substrate was significantly higher than that grown in Rockwool and perlite at any condition tested. This might be addressed to the high chloride and sodium content of $553 \pm 7 \mathrm{mg} \cdot \mathrm{L}^{-1}$ and $290 \pm 63 \mathrm{mg} \cdot \mathrm{L}^{-1}$, respectively, of the coco peat substrate at the start of the experiment. Nevertheless, it must be emphasised that at the stage of ripening, the nutrient solutions had been replaced several times and thus, it would be surprising if the substrate still contains significant plant accessible amounts of these ions originating from the beginning of the experiments. In addition, the chloride and sodium content of leaves of plants grown in coco peat was very similar to that grown in Rockwool and perlite. Thus, the effect was specific for fruits, and the reason for the increased chloride and sodium contents in coco peat-grown fruits remains elusive. However, a higher sodium chloride content in tomato fruits has been reported to be beneficial for the taste of tomato fruits since they are perceived to be sweeter, which may be caused by an improvement in the sensory perception by the presence of sodium chloride [46].

Potassium, the main cation found in tomato fruits, was slightly affected by increasing salinity and no major differences were found between different substrates. In contrast, in leaves, potassium decreased significantly with increasing concentration of sodium chloride in the nutrient solutions, which is in agreement with previous results $[40,44,45]$. Similarly, magnesium was not affected by the sodium chloride concentration in fruits while it decreased slightly in leaves. In contrast, calcium was mainly unaffected by sodium chloride in leaves while it increased in the fruits, which might explain the low level of blossom end rot even in the presence of high sodium chloride concentrations.

Amongst coco peat, Rockwool, and perlite substrates, tomato plants grown in coco peat substrate showed the highest yield at all salinity levels, with a larger number of fruits being produced (Figure 2A,C). The weight of single fruits was not different compared to fruits that were grown in Rockwool and perlite (Figure 2B). In addition, the total soluble solids were higher, coupled to a higher dry matter (Figure 3A,B) and sugar content (Figure 4A,B). Moreover, fruits grown in coco peat had the highest sodium chloride content, which might positively affect the taste, while acidity (Figure 3C,D) and amino acid content (Figure 5) remained with the exception of proline largely unaffected. Thus, coco peat seems to be the most suitable substrate. In addition, it is easier to dispose than Rockwool and perlite.

Our results show that groundwater containing sodium chloride at levels typically found in Malta and probably other islands can be used for the preparation of nutrient solutions for the cultivation of tomatoes. However, there was a clear decrease in the yield compared to control nutrient solutions with low salinity. In fact, the yield decline observed for cherry tomatoes was similar to that reported for round tomatoes [5]. While the yield decreased, the quality of the fruits increased with the sodium chloride concentration, as indicated by the higher contents of total soluble solids, particularly the sugars. Salinity did not have adverse effects on acidity and glutamate content. We could not observe an increase in the GABA content of the fruits. However, the previously reported results were obtained with 'Micro Tom' [37], a variety with physiology different to that of varieties used for human consumption. Thus, the impact of salinity on GABA levels should be investigated in more detail in the future. Another surprising result was that the levels of citric and malic acid were unaffected by the sodium chloride concentration. In contrast to previous results, only a small increase in titratable acidity was observed. This increase was mainly the effect of decreased counter cation levels rather than a change in the concentration of the acids. Taken together, these results demonstrate that cherry tomatoes respond to salt stress in a similar way to round tomatoes, but the acidification seems to be less pronounced, which is a desirable trait.

Supplementary Materials: The following are available online at https:/ / www.mdpi.com/article/ 10.3390/horticulturae8010059/s1, Figure S1: Schematic diagram of the irrigation system, Figure S2: Experimental set up in the greenhouse, Table S1: Greenhouse air temperature and relative humidity, Table S2: Ion composition and EC of the nutrient solutions used, Table S3: Chemicals used for the 
preparation of the stock solutions, Table S4: Amount of salts required for preparation of one litre of a 100-fold stock solution, Table S5: Contents of amino acids in fruits, Supplementary File S1: Raw data for Figures 2-7.

Author Contributions: Conceptualization, C.A., S.v.T. and W.R.; methodology, C.A., S.v.T. and W.R.; writing-original draft preparation, C.A. and W.R.; writing-review and editing, C.A., S.v.T. and W.R.; visualization, C.A. All authors have read and agreed to the published version of the manuscript.

Funding: This research received no external funding.

Institutional Review Board Statement: Not applicable.

Informed Consent Statement: Not applicable.

Data Availability Statement: The raw data obtained in this study are summarised in Supplementary File S1.

Acknowledgments: The authors want to thank Adelheid Vierthaler and Christine Haas for technical assistance with ICP-OES and ion chromatography and Peter Schaich, Enza Zaden Germany for providing Solanum lycopersicum cv. Gustafano seeds. Thanks to Sandra Matthes for critical reading of the manuscript.

Conflicts of Interest: The authors declare no conflict of interest.

\section{References}

1. Panno, S.; Davino, S.; Caruso, A.G.; Bertacca, S.; Crnogorac, A.; Mandić, A.; Noris, E.; Matić, S. A Review of the Most Common and Economically Important Diseases That Undermine the Cultivation of Tomato Crop in the Mediterranean Basin. Agronomy 2021, 11, 2188. [CrossRef]

2. Jones, J.B., Jr. Tomato Plant Culture: In the Field, Greenhouse, and Home Garden; CRC Press: Boca Raton, FL, USA, 2007.

3. Rubatzky, V.E.; Yamaguchi, M. Tomatoes, peppers, eggplants, and other solanaceous vegetables. In World Vegetables; Springer: Boston, MA, USA, 1997; pp. 532-576.

4. Domis, M.; Papadopoulos, A.; Gosselin, A. Greenhouse Tomato Fruit Quality. Hortic. Rev. 2002, 26, $239-349$.

5. Van de Vooren, J.; Welles, G.; Hayman, G. Glasshouse crop production. In The Tomato Crop; Springer: Dordrecht, The Netherlands, 1986; pp. 581-623.

6. Abad, M.; Fornes, F.; Carrion, C.; Noguera, V.; Noguera, P.; Maquieira, A.; Puchades, R. Physical properties of various coconut coir dusts compared to peat. HortScience 2005, 40, 2138-2144. [CrossRef]

7. Jankauskienè, J.; Brazaitytè, A.; Viškelis, P. Effect of different growing substrates on physiological processes, productivity and quality of tomato in soilless culture. In Soilless Culture-Use of Substrates for the Production of Quality Horticultural Crops; IntechOpen: London, UK, 2015.

8. Noguera, P.; Abad, M.; Noguera, V.; Puchades, R.; Maquieira, A. Coconut Coir Waste, a New and Viable Ecologically-Friendly Peat Substitute; International Society for Horticultural Science (ISHS): Leuven, Belgium, 2000.

9. Sorrequieta, A.; Ferraro, G.; Boggio, S.B.; Valle, E.M. Free amino acid production during tomato fruit ripening: A focus on L-glutamate. Amino Acids 2010, 38, 1523-1532. [CrossRef] [PubMed]

10. Agius, C.; Von Tucher, S.; Poppenberger, B.; Rozhon, W. Quantification of Glutamate and Aspartate by Ultra-High Performance Liquid Chromatography. Molecules 2018, 23, 1389. [CrossRef] [PubMed]

11. Boggio, S.B.; Palatnik, J.F.; Heldt, H.W.; Valle, E.M. Changes in amino acid composition and nitrogen metabolizing enzymes in ripening fruits of Lycopersicon esculentum Mill. Plant Sci. 2000, 159, 125-133. [CrossRef]

12. Fuke, S.; Konosu, S. Taste-active components in some foods: A review of Japanese research. Physiol. Behav. 1991, 49, 863-868. [CrossRef]

13. Ecoserv Ltd. Final Report to the Malta Resources Authority on Chemical \& Microbiological Analysis of Groundwater; Ecoserv Ltd.: Mosta, Malta, 2009.

14. Cuartero, J.; Fernández-Muñoz, R. Tomato and salinity. Sci. Hortic. 1998, 78, 83-125. [CrossRef]

15. Leonardi, C.; Martorana, M.; Giuffrida, F.; Fogliano, V.; Pernice, R. Tomato Fruit Quality in Relation to the Content of Sodium Chloride in the Nutrient Solution; International Society for Horticultural Science (ISHS): Leuven, Belgium, 2004.

16. El-Mogy, M.M.; Garchery, C.; Stevens, R. Irrigation with salt water affects growth, yield, fruit quality, storability and marker-gene expression in cherry tomato. Acta Agric. Scand. Sect. B Soil Plant Sci. 2018, 68, 727-737. [CrossRef]

17. Tang, H.; Zhang, X.; Gong, B.; Yan, Y.; Shi, Q. Proteomics and metabolomics analysis of tomato fruit at different maturity stages and under salt treatment. Food Chem. 2020, 311, 126009. [CrossRef]

18. Malash, N.; Ghaibeh, A.; Yeo, A.; Ragab, R.; Cuartero, J. Effect of Irrigation Water Salinity on Yield and Fruit Quality of Tomato; International Society for Horticultural Science (ISHS): Leuven, Belgium, 2002. 
19. Krauss, S.; Schnitzler, W.H.; Grassmann, A.J.; Woitke, M. The influence of different electrical conductivity values in a simplified recirculating soilless system on inner and outer fruit quality characteristics of tomato. J. Agric. Food Chem. 2006, 54, 441-448. [CrossRef]

20. Magán, J.; Gallardo, M.; Thompson, R.; Lorenzo, P. Effects of salinity on fruit yield and quality of tomato grown in soil-less culture in greenhouses in Mediterranean climatic conditions. Agric. Water Manag. 2008, 95, 1041-1055. [CrossRef]

21. Mizrahi, Y. Effect of salinity on tomato fruit ripening. Plant Physiol. 1982, 69, 966-970. [CrossRef]

22. Zushi, K.; Matsuzoe, N. Salt Stress-Enhanced $\hat{\imath}^{3}$-aminobutyric Acid (GABA) in Tomato Fruit; International Society for Horticultural Science (ISHS): Leuven, Belgium, 2007.

23. Loudari, A.; Benadis, C.; Naciri, R.; Soulaimani, A.; Zeroual, Y.; El Gharous, M.; Kalaji, H.M.; Oukarroum, A. Salt stress affects mineral nutrition in shoots and roots and chlorophyll a fluorescence of tomato plants grown in hydroponic culture. J. Plant Interact. 2020, 15, 398-405. [CrossRef]

24. Alfocea, F.P.; Caro, M. Response of tomato cultivars to salinity. Plant Soil 1993, 150, 203-211. [CrossRef]

25. Shiyab, S.M.; Shatnawi, M.A.; Shibli, R.A.; Al Smeirat, N.G.; Ayad, J.; Akash, M.W. Growth, nutrient acquisition, and physiological responses of hydroponic grown tomato to sodium chloride salt induced stress. J. Plant Nutr. 2013, 36, 665-676. [CrossRef]

26. Zhang, Y.; Kaiser, E.; Zhang, Y.; Yang, Q.; Li, T. Short-term salt stress strongly affects dynamic photosynthesis, but not steady-state photosynthesis, in tomato (Solanum lycopersicum). Environ. Exp. Bot. 2018, 149, 109-119. [CrossRef]

27. Sgherri, C.; Kadlecová, Z.; Pardossi, A.; Navari-Izzo, F.; Izzo, R. Irrigation with Diluted Seawater Improves the Nutritional Value of Cherry Tomatoes. J. Agric. Food Chem. 2008, 56, 3391-3397. [CrossRef]

28. De, P.; Martino, A.; Raimondi, G.; Maggio, A. Comparative analysis of water and salt stress-induced modifications of quality parameters in cherry tomatoes. J. Hortic. Sci. Biotechnol. 2007, 82, 283-289. [CrossRef]

29. Al Hassan, M.; Martinez Fuertes, M.; Ramos Sanchez, F.J.; Vicente, O.; Boscaiu, M. Effects of Salt and Water Stress on Plant Growth and on Accumulation of Osmolytes and Antioxidant Compounds in Cherry Tomato. Not. Bot. Horti Agrobot. Cluj-Napoca 2015, 43, 1-11. [CrossRef]

30. Gonzalez-Cebrino, F.; Lozano, M.; Ayuso, M.C.; Bernalte, M.J.; Vidal-Aragon, M.C.; González-Gómez, D. Characterization of traditional tomato varieties grown in organic conditions. Span. J. Agric. Res. 2011, 9, 444-452. [CrossRef]

31. Beckles, D.M. Factors affecting the postharvest soluble solids and sugar content of tomato (Solanum lycopersicum L.) fruit. Postharvest Biol. Technol. 2012, 63, 129-140. [CrossRef]

32. Pardossi, A.; Carmassi, G.; Diara, C.; Incrocci, L.; Maggini, R.; Massa, D. Fertigation and Substrate Management in Closed Soilless Culture; University of Pisa: Pisa, Italy, 2011.

33. Hu, Y.; Burucs, Z.; von Tucher, S.; Schmidhalter, U. Short-term effects of drought and salinity on mineral nutrient distribution along growing leaves of maize seedlings. Environ. Exp. Bot. 2007, 60, 268-275. [CrossRef]

34. Agius, C.; von Tucher, S.; Poppenberger, B.; Rozhon, W. Quantification of sugars and organic acids in tomato fruits. MethodsX 2018, 5, 537-550. [CrossRef] [PubMed]

35. Zhang, X.; Zhao, T.; Cheng, T.; Liu, X.; Zhang, H. Rapid resolution liquid chromatography (RRLC) analysis of amino acids using pre-column derivatization. J. Chromatogr. B Anal. Technol. Biomed. Life Sci. 2012, 906, 91-95. [CrossRef]

36. Panthee, D.R.; Labate, J.A.; McGrath, M.T.; Breksa, A.P.; Robertson, L.D.; Iii, A.P.B. Genotype and environmental interaction for fruit quality traits in vintage tomato varieties. Euphytica 2013, 193, 169-182. [CrossRef]

37. Yin, Y.-G.; Tominaga, T.; Iijima, Y.; Aoki, K.; Shibata, D.; Ashihara, H.; Nishimura, S.; Ezura, H.; Matsukura, C. Metabolic alterations in organic acids and $\gamma$-aminobutyric acid in developing tomato (Solanum lycopersicum L.) fruits. Plant Cell Physiol. 2010, 51, 1300-1314. [CrossRef]

38. Besford, R.T.; Maw, G.A. Effect of potassium nutrition on tomato plant growth and fruit development. Plant Soil 1975, 42, 395-412. [CrossRef]

39. Sonneveld, C.; Welles, G. Yield and quality of rockwool-grown tomatoes as affected by variations in EC-value and climatic conditions. Plant Soil 1988, 111, 37-42. [CrossRef]

40. Adams, P. Effects of increasing the salinity of the nutrient solution with major nutrients or sodium chloride on the yield, quality and composition of tomatoes grown in rockwool. J. Hortic. Sci. 1991, 66, 201-207. [CrossRef]

41. Halmann, E.; Kobryń, J. Yield and quality of cherry tomato (Lycopersicon esculentum var. cerasiforme) cultivated on rockwool and cocofibre. In Proceedings of the VI International Symposium on Protected Cultivation in Mild Winter Climate: Product and Process Innovation 614, Ragusa-Sicilia, Italy, 5-8 March 2002.

42. Zushi, K.; Matsuzoe, N. Free amino acid contents of tomato fruit grown under water and salinity stresses. In Proceedings of the IX International Symposium on the Processing Tomato 724, Melbourne, Australia, 15-18 November 2004.

43. Claussen, W.; Brückner, B.; Krumbein, A.; Lenz, F. Long-term response of tomato plants to changing nutrient concentration in the root environment-the role of proline as an indicator of sensory fruit quality. Plant Sci. 2006, 171, 323-331. [CrossRef]

44. Giuffrida, F.; Martorana, M.; Leonardi, C. How sodium chloride concentration in the nutrient solution influences the mineral composition of tomato leaves and fruits. HortScience 2009, 44, 707-711. [CrossRef]

45. Maggio, A.; Raimondi, G.; Martino, A.; De Pascale, S. Salt stress response in tomato beyond the salinity tolerance threshold. Environ. Exp. Bot. 2007, 59, 276-282. [CrossRef]

46. Petersen, K.K.; Willumsen, J.; Kaack, K. Composition and taste of tomatoes as affected by increased salinity and different salinity sources. J. Hortic. Sci. Biotechnol. 1998, 73, 205-215. [CrossRef] 